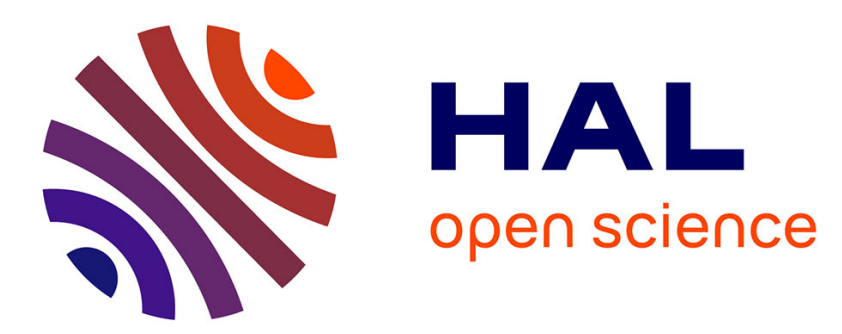

\title{
Strategic Capacity Planning in Supply Chain Design for a New Market Opportunity
}

Satyaveer Singh Chauhan, Rakesh Nagi, Jean-Marie Proth

\section{To cite this version:}

Satyaveer Singh Chauhan, Rakesh Nagi, Jean-Marie Proth. Strategic Capacity Planning in Supply Chain Design for a New Market Opportunity. [Research Report] RR-4658, INRIA. 2002, pp.12. inria00071927

\section{HAL Id: inria-00071927 \\ https://hal.inria.fr/inria-00071927}

Submitted on 23 May 2006

HAL is a multi-disciplinary open access archive for the deposit and dissemination of scientific research documents, whether they are published or not. The documents may come from teaching and research institutions in France or abroad, or from public or private research centers.
L'archive ouverte pluridisciplinaire HAL, est destinée au dépôt et à la diffusion de documents scientifiques de niveau recherche, publiés ou non, émanant des établissements d'enseignement et de recherche français ou étrangers, des laboratoires publics ou privés. 


\title{
Strategic Capacity Planning in Supply Chain Design for a New Market Opportunity
}

\author{
Chauhan Satyaveer S. - Nagi Rakesh — Proth Jean-Marie
}

\section{$\mathbf{N}^{\circ} 4658$}

November 2002

THÈME 4 



\title{
RINRIA
}

\section{Strategic Capacity Planning in Supply Chain Design for a New Market Opportunity}

\author{
Chauhan Satyaveer S. ${ }^{* \dagger}$, Nagi Rakesh ${ }^{\ddagger}$, Proth Jean-Marie ${ }^{\S}$ \\ Thème 4 - Simulation et optimisation \\ de systèmes complexes \\ Projet SAGEP
}

Rapport de recherche $\mathrm{n}^{\circ} 4658$ - November $2002-12$ pages

\begin{abstract}
This paper addresses the problem of supply chain design at the strategic level when production/distribution of a new market opportunity has to be launched in an existing supply chain. The new market opportunity is characterized by a deterministic forecast expected to occur per period. The product (or service) is assumed to be produced (or provided) in a three-stage capacitated supply chain where the first stage concerns suppliers, the second stage producers and the final stage customers. There could be multiple alternatives at each stage which are defined as nodes. Nodes in each stage are connected to the next stage through capacitated transportation systems. Production capacity at the second stage (i.e., producers) are also limited since they may already be involved in other existing activities. The objective is to perform strategic capacity planning in the supply chain in order to meet the demand of the new opportunity at minimal cost. A linear running cost is associated to each node. If the decision is to increase the capacity of a node, then a fixed cost applies followed by a cost that is proportional to the additional capacity

The overall problem can be modelled as a large-scale mixed integer linear programming problem. A solution algorithm is developed to overcome difficulties associated with the size of the problem, and is tested on empirical data sets. The overall contribution is an analytical tool that can be employed by the managers responding to the new market opportunity at the strategic level for supply chain design.
\end{abstract}

Key-words: Capacity Planning, Supply Chain Design, Strategic Decisions

\footnotetext{
* chauhan@loria.fr

$\dagger$ corresponding author

$\ddagger$ nagi@acsu.buffalo.edu

$\S$ proth@loria.fr
} 


\section{Ordonnancement des capacités au niveau stratégique dans la conception d'une chaîne l'approvisionnement}

Résumé : Ce papier s'intéresse à ladaptation dune chaîne d'approvisionnement au lancement dune nouvelle gamme de produit ou dun nouveau service de la production à la distribution. Nous nous plaçons au niveau stratégique. La nouvelle opportunité de marché est caractérisée par des projections déterministes de ce qui sera supposé se produire par période de temps. Le produit (ou service) est supposé être produit (ou fourni) dans une chaîne d'approvisionnement décomposée en trois échelons : le premier concerne les fournisseurs, le second les producteurs et le troisième les consommateurs. Chaque étape est définie comme un nud et peut comporter plusieurs alternatives : les nuds d'un échelon sont connecté à l'échelon suivant à l'aide d'un système de transport à capacité limitée. La capacité de la production pour la deuxième étape (c.-à-d. la production) est aussi limitée puisquelle peut déjà être utilisée par une autre activité. L'objectif est d'effectuer une planification des capacités stratégiques d'une chaîne d'approvisionnement pour faire face à la demande associée à la nouvelle opportunité, et cela à un coût minimal. Un coût d'exploitation linéaire est associé à chaque nud. Si la décision est daugmenter la capacité d'un nud, alors apparait un coût dinvestissement composé dun coût fixe complété par un coût proportionnel à la capacité supplémentaire. L'ensemble du problème peut être modélisé comme un problème de programmation linéaire de grande taille dont la solution admet des variables entières. L'approche proposée permet de contourner les difficultés dues à la taille du problème et est évaluée à l'aide d'exemples générés aléatoirement. Le résultat final est un outil d'analyse pouvant être employé par des managers réagissant à une nouvelle opportunité du marché pour la conception de chaîne d'approvisionnement au niveau stratégique.

Mots-clés : Planification des capacités, Conception des chaîne l'approvisionnement, Décisions stratégiques 


\section{Introduction}

Supply chain networks are considered as solutions for effectively meeting customer requirements such as low costs, high product variety, quality and shorter lead times. The success of a supply chain lies in good strategic and tactical planning and monitoring at the operational level. Strategic planning is long term planning and usually consists in selecting providers and distributors, location and capacity planning of manufacturing/servicing units, among others. In the context of supply chain design we usually consider two aspects in selection of partners: the qualitative aspect and the quantitative aspect. The qualitative aspects are the primary selection criteria, as for example, financial position of partner, quality policy, previous history, adaptivity towards change of product type or market situations.

In quantitative selection criteria we usually consider the cost effectiveness of the partners with respect to supply chain. This consideration involves, for example, capacity planning, transportation network design, identification of distributors in potential market. Plenty of models are discussed in literature. In [2] authors proposed a model of supply chain network composed of three stages ,supplier network, producer network and distributor network, and defined the nature of relationship between each stage. In [1] a strategic model structure and a hierarchical decomposition approach for the supply chain are presented. [10] presented a network equilibrium model and discussed qualitative properties of the model. For an extensive review on strategic production-distribution models in a global supply environment, the reader is referred to [6] and [12].

In this paper we restrict ourselves to strategic capacity planning only. We consider the case of supply chain design for a new market opportunity when demand in each period is known. All the potential partners have limited capacity (production and transportation) and the capacity can be increased by introducing the new resources. The problem is to select providers and producers among the available ones. The problem is modeled as a mixed integer programming problem and the difficulty arises when the number of integer variables increases.

Integer linear programming problems constitute a subclass of combinatorial optimization problems [7]. Many problem specific algorithm exist for finding the feasible solutions or even optimal solutions. Three basic methods, Branch-and-Bound [9], Cutting plane algorithm, and Dynamic programming are widely used for solving Integer linear programming problems [13]. Some time these methods are used in conjunction with others, for instance when cutting plane method is used with Branch-and-Bound, the technique is known as Branch-and-cut algorithms [8] and when the column generation [4] is used in conjunction with Branchand-bound, it is refer as Branch-and-price [11]. All the algorithms using branch-and-bound require good starting bound which is usually obtained by LP relaxations. Langrangian relaxation [5] and [3] is one of the available methods to obtain the good feasible bound.

In solving combinatorial optimization problem, there is always a trade-off between computational time and quality of the solution. In this paper we present an heuristic approach to find a good solution. Latterly, this solution can be used as an upper bound for the Branch-and-bound algorithm developed to reach the optimal solution. 
The remainder of the paper is organized as follows. Section 2 presents the problem description and formulation. The solution approach based on the key properties is presented in Section 3. Numerical results of a computational study are presented in Section 4. Finally, conclusions are presented in Section 5.

\section{Problem Description and Formulation}

\subsection{Problem Description}

We consider a three-echelon system in which the first echelon concerns providers, the second echelon concerns producers and the last echelon concerns distributors. We assume that all the partners under consideration already met the pre-requisite requirements. All distributors have a definite demand in each period on a given horizon. Providers provide the raw material/semi-finished products to selected producers and these producers fulfil the demand of each distributor. Each provider and producer has his production cost and transportation costs to the next stage. These costs are invariant in time. The transportation costs vary from one pair (provider-producer and producer-distributor) to another. Each provider and the producer has limited production and transportation capacities. The transportation and production capacities can be extended by investing on resources. We assume that investment is only possible at the beginning of the first period. The transportation costs and the production costs are linear functions of quantities. Investment cost is also a linear function of quantity, but with additional fixed cost which do not depend upon quantities but only on the entities it is related to. The problem is to select the most economic combination of providers and producers such that they satisfy the demand imposed by all individual distributors.

\subsection{Mixed integer programming formulation}

Let $i \in\{1,2, \ldots, P\}$ be the providers,$j \in\{1,2, \ldots, M\}$ be the producers and $k \in\{1,2, \ldots, D\}$ be the distributors. The demand is deterministic and is known for each distributor on time horizon $T$. We consider four investments in this model: investment to enhance the capacity of providers, investment to enhance the capacity of producers and investment to enhance the transportation capacity between provider-producer and producer-distributor. The notations used are as follows:

$p_{i} \quad$ : Raw material cost per unit at provider $i$

$m_{j} \quad$ : Production cost per unit at producer $j$

$R_{i, j} \quad$ : Available transportation capacity from provider $i$ to producer $j$

$r_{i, j} \quad$ : Added transportation capacity from provider $i$ to producer $j$

$S_{j, k} \quad$ : Available transportation capacity from producer $j$ to distributor $k$

$s_{j, k} \quad$ :Added transportation capacity from producer $j$ to distributor $k$

$G_{i} \quad$ : Available production capacity for provider $i$

$g_{i} \quad$ :Added production capacity for provider $i$ 
$H_{j} \quad$ :Available production capacity for producer $j$

$h_{j} \quad$ :Added production capacity for producer $j$

$\alpha \quad$ : Discount rate

$\beta \quad$ :Depreciation factor

$x_{i, j}^{t} \quad$ : Raw material shipped from provider $i$ to producer $j$ in period $t$

$y_{j, k}^{t} \quad$ : Product shipped from producer $i$ to distributor $k$ in period $t$

In this model, we have the following four-investment costs:

Investment cost for new transportation capacity $r_{i, j}$ from provider $i$ to producer $j$

Cost $=\left\{\begin{array}{cccc}A_{i, j}+a_{i, j} & r_{i, j} & \text { if } & r_{i, j}>0 \\ 0 & \text { if } & r_{i, j}=0\end{array}\right\}$

Investment cost for new transportation capacity $s_{j, k}$ from producer $j$ to distributor $k$



Investment for provider $i$ to enhance its capacity by $g_{i}$,

Cost $=\left\{\begin{array}{ccc}E_{i}+e_{i} g_{i} & \text { if } & g_{i}>0 \\ 0 & \text { if } & g_{i}=0\end{array}\right\}$

Investment for producer $j$ to enhance its capacity by $h_{j}$

Cost $=\left\{\begin{array}{cll}F_{j}+f_{j} h_{j} & \text { if } & h_{j}>0 \\ 0 & \text { if } & h_{j}=0\end{array}\right\}$

Now, the problem that we denote by $P_{1}$ can be formulated as follows:

$$
\begin{gathered}
P_{1} \quad \operatorname{MIN} \sum_{t=1}^{T} \sum_{i=1}^{P} \sum_{j=1}^{M} C_{t}\left(p_{i}+u_{i, j}\right) x_{i, j}^{t}+\sum_{t=1}^{T} \sum_{j=1}^{M} \sum_{k=1}^{D} C t\left(m_{j}+v_{j, k}\right) y_{j, k}^{t}+ \\
\sum_{i=1}^{P} \sum_{j=1}^{M}\left(C_{1}-D_{1}\right)\left(a_{i, j} r_{i, j}+A_{i, j} U_{i, j}\right)+\sum_{j=1}^{M} \sum_{k=1}^{D}\left(C_{1}-D_{1}\right)\left(b_{j, k} s_{j, k}+B_{j, k} V_{j, k}\right)+ \\
\sum_{i=1}^{P}\left(C_{1}-D_{1}\right)\left(e_{i} g_{i}+E_{i} W_{i}\right)+\sum_{j=1}^{M}\left(C_{1}-D_{1}\right)\left(f_{j} h_{j}+F_{j} X_{j}\right)
\end{gathered}
$$

Subjected to:

$$
\begin{aligned}
& x_{i, j}^{t} \leq R_{i, j}+r_{i, j} ; \quad t \in\{1, \ldots, T\}, i \in\{1,2, \ldots, P\}, j \in\{1,2, \ldots, M\}, \\
& y_{j, k}^{t} \leq S_{j, k}+s_{j, k} ; \quad t \in\{1, \ldots, T\}, i \in\{1,2, \ldots, P\}, j \in\{1,2, \ldots, M\},
\end{aligned}
$$




$$
\begin{gathered}
\sum_{j=1}^{M} x_{i, j}^{t} \leq G_{i}+g_{i} ; \quad i \in\{1,2, \ldots, P\}, \quad t \in\{1,2, \ldots, T\} \\
\sum_{k=1}^{D} y_{j, k}^{t} \leq H_{j}+h_{j} ; \quad j \in\{1,2, \ldots, M\}, \quad t \in\{1,2, \ldots, T\} \\
\sum_{i=1}^{p} x_{i, j}^{t}=\sum_{k=1}^{d} y_{j, k}^{t} ; \quad t \in\{1, \ldots, T\}, j \in\{1,2, \ldots, M\}, \\
\sum_{j=1}^{M} y_{j, k}^{t}=d_{k}^{t} ; \quad t \in\{1, \ldots, T\}, k \in\{1,2, \ldots, D\}, \\
r_{i, j} \leq Z_{i, j}^{r} . U_{i, j} ; \quad i \in\{1,2, \ldots, P\}, j \in\{1,2, \ldots, M\}, \\
s_{j, k} \leq Z_{j, k}^{s} . V_{j, k} ; \quad j \in\{1,2, \ldots, M\}, k \in\{1,2, \ldots, D\}, \\
g_{i} \leq Z_{i}^{g} . W_{i} ; \quad i \in\{1,2, \ldots, P\}, \\
h_{j} \leq Z_{j}^{h} . X_{j} ; \quad j \in\{1,2, \ldots, M\}, \\
U_{i, j} \in\{0,1\}, V_{j, k} \in\{0,1\}, W_{i} \in\{0,1\}, X_{j} \in\{0,1\}, \\
C_{t}=(1+\alpha)^{T-t+1}, D_{t}=(1-\beta)^{T-t+1} \quad t \in\{1,2, \ldots, T\},
\end{gathered}
$$

In the above formulation, the constraints (1) and (2) guarantee that the shipment must be less than or equal to the available transportation capacity $R_{i, j}+r_{i, j}$ and $S_{j, k}+s_{j, k}$ respectively. Similarly, (3) and (4) constraints guarantee that the delivery in each period must not exceed the capacity. Constraint (5) guarantees that total shipment, in each period, from all providers to all producers must be equal to the total shipment from all producers to all distributors. Constraint (6) guarantees that total shipment from all producers to any distributor in each period must be equal to the demand of the distributor in that period. $Z_{j, k}^{s}, Z_{i, j}^{r}, Z_{i}^{g}$, and $Z_{j}^{h}$ are big numbers greater than the total demand and $U_{i, j}, V_{i, j}, W_{i}$ and $X_{j}$ are binary integer variables. These binary variables are associated with fixed cost in objective function and take positive values only if capacities enhancements are made.

The problem would be simple and can be solved using Minimum cost flow algorithm efficiently if we knew precisely the investment locations. The problem arises when we introduce binary variables and the size of problem is large. For instance, the number of binary variables required for this problem is $(P+M+P M+M D)$. The above formulation is mixed integer-programming formulation.

We denote by $P_{2}^{1}$, the problem $P_{1}$ in which the variables $U_{i, j}, V_{i, j}, W_{i}$ and $X_{j}$ can take any value in $[0,1]$. Thus, $P_{2}^{1}$ is obtained by relaxing constraints (11) in $P_{1}$. 


\section{Properties and solution approach}

\subsection{Result1}

There exist at least one optimal solution to the problem $P_{2}$ in which constraints (7) to (10) are saturated.

Proof

Assume for instance, that $g_{i}<Z_{i}^{g} W_{i}$ for an optimal solution $S_{1}$. Then consider a solution $S_{2}$ that is the same as $S_{1}$, except that $W_{i}=g_{i} / Z_{i}$. $S_{2}$ is still feasible.

Furthermore,

$$
C\left(S_{1}\right)-C\left(S_{2}\right)=E_{i}\left(W_{i}-g_{i} / Z_{i}\right) \geq 0
$$

where $\mathrm{C}($.$) denotes the cost related to solution(.). Since E_{i} \geq 0, C\left(S_{1}\right) \geq C\left(S_{2}\right)$. Two cases are possible: either $C\left(S_{1}\right)>C\left(S_{2}\right)$ and $S_{1}$ is not optimal, which is contradictory to the hypothesis, or $C\left(S_{1}\right)=C\left(S_{2}\right)$, and $S_{2}$ and $S_{1}$ are both optimal. This completes the proof.

\section{Corollary}

Since there exists at least one optimal solution such that constraints (7) to (10)are saturated, we can reduce the size of the problem $P_{2}$ by replacing $U_{i, j}$ by $r_{i, j} / Z_{i, j}^{r}, V_{j, k}$ by $s_{j, k} / Z_{j, k}^{s}, W_{i}$ by $g_{i} / Z_{i}^{g}$ and $X_{j}$ by $h_{j} / Z_{j}^{h}$ in the objective function and removing all the constraints $(7)$ to (11).

\section{$3.2 \quad$ Result2}

For $m=1,2, \ldots$, we denote by $P_{2}^{m}$ the problem obtained by:

- replacing $Z_{i, j}^{r}\left(\operatorname{resp} . Z_{j, k}^{s}, Z_{i}^{g}\right.$, and $Z_{j}^{h}$ ) by $r_{i, j}^{m-1}$ (resp. $s_{j, k}^{m-1}, g_{i}^{m-1}$, and $h_{i}^{m-1}$ ) if $r_{i, j}^{m-1}>0$ (resp. $s_{j, k}^{m-1}>0, g_{i}^{m-1}>0$, and $h_{i}^{m-1}>0$ ),

- keeping the previous value of $Z_{i, j}^{r}\left(\operatorname{resp} . Z_{j, k}^{s}, Z_{i}^{g}\right.$, and $Z_{j}^{h}$ ) otherwise, where $r_{i, j}^{m-1}, s_{j, k}^{m-1}, g_{i}^{m-1}$ and $h_{i}^{m-1}$ belong to the optimal solution of $P_{2}^{m-1}$

Then:

1. We can derive a feasible solution of $P_{1}$ from the optimal solution of $P_{2}^{m}$ by setting $U_{i, j}=1$ (resp. $V_{j, k}=1, W_{i}=1$, and $X_{j}=1$ ) when $r_{i, j}^{m}>0$ (resp. $s_{j, k}^{m}, g_{i}^{m}>0$, and $h_{i}^{m}>0$ ) and solving the new problem that we will call $P_{3}^{m}$.

2. Let $S_{2}^{m}$ be the optimal solution of $P_{2}^{m}$, then there exists $m^{*}$ such that $S_{2}^{m^{*}}$ is a feasible solution of $P_{1}$.

\section{Proof}

1. The solution $S_{2}^{m}$ verifies constraints (1) to (6) of problem $P_{2}^{m}$, which are also constraints of $P_{1}$. Furthermore, in solution $S_{2}^{m}$, constraints (7) to (10) are saturated and $U_{i, j}, V_{j, k}, W_{i}$, and $X_{j} \in[0,1]$. They remain satisfied if these variables are fixed to 1 if the corresponding additional capacity is strictly positive. Then solving the problem $P_{3}^{m}$, we obtain a solution that is feasible for $P_{1}$. This completes the proof of the first part of the result.

2. Consider the variables $r_{i, j}$ and $U_{i, j}$ that concern the transportation from providers to producers. According to result 1 and the hypothesis given in result $2, r_{i, j}^{m}=a^{m-1} \cdot U_{i, j}^{m}$ replaces the constraint (7), where $a^{m-1}$ is: 
- either equal to $r_{i, j}^{M}, M<m$, where $M$, the greatest integer such that $r_{i, j}^{M}>0$, belongs to the optimal solution of $P_{2}^{M}$, if any

- or equal to the initial values of $Z_{i, j}^{r}$ if $r_{i, j}^{k}=0$ for $k=1,2, \ldots, m-1$. Thus we have to consider two cases:

Case1:

$U_{i, j}^{k}=r_{i, j}^{k} / r_{i, j}^{M_{k}}$, where $M_{k}<k$ is defined as $M$. This leads to:

$\prod_{k=2}^{m} U_{i, j}^{k}=\prod_{k=2}^{m}\left(r_{i, j}^{k} / r_{i, j}^{M_{k}}\right)=r_{i, j}^{m} / r_{i, j}^{M_{1}}$,and

$$
r_{i, j}^{m}=r_{i, j}^{M_{1}} \prod_{k=2}^{m} U_{i, j}^{k}
$$

Since $U_{i, j}^{k} \in[0,1]$, we see that $r_{i, j}^{k}$ decreases with $k$ i.e. with the number of iterations.

Case2:

$r_{i, j}^{k}=0$ for $k=1,2, \ldots, m-1$, and the next value of this variables, that is $r_{i, j}^{m}$, can only be obtained by solving $P_{2}^{m}$. Let $E_{k}$ be the set of variables $r_{i, j}$ that are strictly positive in the optimal solution $S_{2}^{k}$ of $P_{2}^{k}$, and $F_{k}$ be the set of variables that are equal to zero in $S_{2}^{k}$. Whatever $k=1,2, \ldots$, we know that:

$$
\sum_{i \in E_{k}} r_{i, j}^{k}=\text { constant }
$$

since this quantity is the sum of the additional capacities, that is a constant (see problem $P_{1}$ and $\left.P_{2}^{k}\right)$. Furthermore, if the same variable $r_{i, j}$ belongs to $E_{k_{1}}$ and $E_{k_{2}}, k_{2}>k_{1}$ then according to (14):

$$
r_{i, j}^{k_{2}} \leq r_{i, j}^{k_{1}}
$$

Since the number of variables $r_{i, j}$ is finite, the number of sets $E_{k}, k=1,2, \ldots$ is finite. But this sequence of sets has the following property:

if $m_{2}>m_{1}$, we cannot have $E_{m_{2}} \subset E_{m_{1}}$. The proof is straight foreward:

If we had $E_{m_{2}} \subset E_{m_{1}}$, we would have:

$\sum_{r_{i, j} \in E_{m_{2}}} r_{i, j}^{m_{2}} \leq \sum_{r_{i, j} \in E_{m_{2}}} r_{i, j}^{m_{1}}($ see 16$)$

and:

$\sum_{r_{i, j} \in E_{m_{2}}} r_{i, j}^{m_{1}}<\sum_{r_{i, j} \in E_{m_{1}}} r_{i, j}^{m_{1}}$ since $E_{m_{2}} \subset E_{m_{1}}$

Thus: $\sum_{r_{i, j} \in E_{m_{2}}} r_{i, j}^{m_{2}}<\sum_{r_{i, j} \in E_{m_{1}}} r_{i, j}^{m_{1}}$.

But we know that (see 14) $\sum_{r_{i, j} \in E_{m_{2}}} r_{i, j}^{m_{2}}=\sum_{r_{i, j} \in E_{m_{1}}} r_{i, j}^{m_{1}}$. This contradiction proves the above claim.

As a consequence, there exists $m_{1}$ and $m_{2}$ such that $E_{m_{1}} \subseteq E_{m_{2}}$. If $E_{m_{2}}=E_{m_{1}}$, solutions $S_{2}^{m_{1}}$ and $S_{2}^{m_{2}}$ are identical and are feasible solution of $P_{1}$ since the binary variables are 0 or 1. If $E_{m_{1}} \subset E_{m_{2}}$, we see that the size of $E_{m}$ will converge since it is limited by the number of variables $r_{i, j}$ and we return to the previous case.

The same proof can be applied to variables $s_{j, k}, g_{i}, h_{i}$ and the related binary variables. This completes the proof. 


\subsection{Solution method}

We utilize the result 1 and result 2 to develop the algorithm.

\subsubsection{Initilization}

To initialize the variables $Z_{i, j}^{r}$, we take the sum of the maximum demand of all distributors on periods $1,2, \ldots, T$. This value is an upper bound of the $Z_{i, j}^{r}$ values that represent the additional transportation capacities from provider to producers. We subtract the available transportation capacity $R_{i, j}$ from the obtained sum. If the difference is negative, we set zero. We apply the similar process for each one of the sets $\left\{Z_{j, k}^{s}\right\},\left\{Z_{i}^{g}\right\}$, and $\left\{Z_{j}^{h}\right\}$.

\subsubsection{Algorithm}

In this algorithm, we derive a feasible solution of $P_{1}$ from each $S_{2}^{m}$, optimal solution of $P_{2}^{m}$ as mentioned in the first part of result 2. We keep the best of the feasible solutions of $P_{1}$ obtained along the iterations.

Remarks We introduced a mechanism that forced the solutions $S_{2}^{m}$ of problem $P_{2}^{m}$ to converge to a feasible solution of $P_{1}$, but we cannot claim that this feasible solution is optimal for $P_{1}$ since the mechanism introduced additional constraints to the set of feasible solutions of $P_{1}$, and thus reduce this set.

\section{$4 \quad$ Numerical examples}

In this section we present the solutions to 10 randomly generated examples and compare the solution with the corresponding optimal solutions. All the examples are generated for five providers, five producer, five distributors and for five time periods. The range of different parameters are as follows:

Available production capacities of providers :0-500

Available transportation capacities of providers :0-500

Production cost of providers :5-10

Available production capacities of producers :0-500

Available transportation capacities of producers :0-500

Production cost of producers :20-35

Investment costs :1000-5000

Proportional investment costs : $1-10$

Demands of all distributors : $100-500$

The optimal solution is obtained using a branch-and-bound algorithm. The results are presented in table1.

As we can see in these results, the solutions provided by the heuristic approach are close, if not identical, to the optimal solutions. None of these examples required more than ten iterations in order that $P_{2}^{m}$ provide a feasible solution of $P_{1}$. 
Table 1: Result

\begin{tabular}{|c|c|c|c|}
\hline & Algorithm solution & Optimal solution & Percentage error \\
\hline 1. & 276518 & 275781 & 0.267 \\
\hline 2. & 257359 & 257359 & 0.0 \\
\hline 3. & 324934 & 322973 & 0.607 \\
\hline 4. & 292007 & 292007 & 0.0 \\
\hline 5. & 354365 & 354116 & 0.070 \\
\hline 6. & 322126 & 325881 & 1.910 \\
\hline 7. & 334013 & 333499 & 0.154 \\
\hline 8. & 321299 & 319871 & 0.446 \\
\hline 9. & 291253 & 290190 & 0.366 \\
\hline 10. & 310869 & 310869 & 0.0 \\
\hline
\end{tabular}

\section{Conclusion}

In general, solving linear integer programming problems are difficult because of its combinatorial nature. In this paper the goal was to develop a good solution method for this specific problem without using linear integer programming methods. In our approach, because of the equality constraints in demand and supply, the heuristic algorithm which modifies the $Z$ value at each iteration, performed well. This heuristic solution can further be used as an upper bound for the branch-and-bound algorithm, if the optimal solution is of prime importance. The performance of the algorithm can be improved by using column generation method for solving the sub-linear programming problems.

\section{Acknowledgments}

Rakesh Nagi gratefully acknowledges the support of National Science Foundation's International Supplement to grant DMI-9800429. Jean-Marie Proth would like to acknowledge INTAS 00-217 that provided financial support for this work.

\section{References}

[1] Morris A Cohen and Hau L Lee. "Strategic analysis of integrated productiondistribution systems: models and methods". Operations Research, 36(2):216-228, 1988. 
[2] S. Selçuk Erengüç, N.C.Simpson, and Asoo J. Vakharia. "Integrated production/distribution planning in supply chains: An invited review". European journal of operational research, 115:219-236, 1999.

[3] Fisher.M. "An application orientated guide to langrangian relaxation ". Interfaces 15, 2:10-21, 1985.

[4] Dantzig G.B. and P. Wolfe. "Decomposition principles for linear programming.". $O p$ erations research, 8:101-111, 1960.

[5] A. Geoffrion. Langrangian relaxation for integer programming. Mathematical programming study2: Approaches to Integer programming Balinski New York: North-Holland, pages $82-114,1974$.

[6] Manish Govil and Jean-Marie Proth. Supply Chain Design and Management: Strategic and Tactical Perspectives. Academic Press, 2002.

[7] Erwin Hans. Resource loading by Branch-and-Price techniques. PhD thesis, Beta research school for operations management and logistics, 2001.

[8] Hoffman K. and M. Padberg. "LP-based combinatorial problem solving.". Annals of Operations Research, 4:145-194, 1985.

[9] L.G. Mitten. "Branch-and-bound methods: General formulation and properties.". $O p$ erations Research, 5:268-279, 1970.

[10] Anna Nagurney, June Dong, and Ding Zhang. "A supply chain network equilibrium model". Transportation Research Part E, 38:281-303, 2002.

[11] Vance P.H., C. Barnhard, E.L.Johnson, and G.L.Nemhauser. "Solving binary cutting stock problems by column generation and branch-and-bound.". Computational optimization and applications, 3:111-130, 1994. 
[12] Carlos J Vidal and Marc Goetschalckx. "Strategic production-distribution models: A critical review with emphasis on global supply chain models". European Journal of Operational Research, 98:1-18, 1997.

[13] Wayne L. Winston. Operations research application and algorithms. Duxbury press, 1993. 
Unité de recherche INRIA Lorraine

LORIA, Technopôle de Nancy-Brabois - Campus scientifique

615, rue du Jardin Botanique - BP 101 - 54602 Villers-lès-Nancy Cedex (France)

Unité de recherche INRIA Rennes : IRISA, Campus universitaire de Beaulieu - 35042 Rennes Cedex (France)

Unité de recherche INRIA Rhône-Alpes : 655, avenue de l'Europe - 38330 Montbonnot-St-Martin (France)

Unité de recherche INRIA Rocquencourt : Domaine de Voluceau - Rocquencourt - BP 105 - 78153 Le Chesnay Cedex (France)

Unité de recherche INRIA Sophia Antipolis : 2004, route des Lucioles - BP 93 - 06902 Sophia Antipolis Cedex (France) 